\title{
Collaboration via co-authorship trends in Government of Canada forestry research
}

\author{
by Heather MacDonald ${ }^{1 *}$, Daniel W. McKenney ${ }^{1}$ and Kaitlin DeBoer ${ }^{1}$
}

\begin{abstract}
As part of its long history, the Canadian Forest Service (CFS) has a mandate to collaborate and share its scientific research. Publishing peer-reviewed scientific literature is an important part of this process. Using a database of CFS publications over the past fifty years, we highlight the continuing publication record of this sector of the Canadian government. The average number of authors reported in the CFS bookstore increased from 1.4 authors per article in the 1960s and 1.5 in the 1970s to just under five authors per publication from 2010 to 2018. Our work also illustrates challenges with longitudinal analysis of citation databases. In particular, use of a popular citation database resulted in significantly fewer articles authored by one person, and significantly more articles with twenty or more authors compared to the publicly available CFS "bookstore" of publications. Based on our findings, we outline a number of recommendations for use of citation data to inform collaboration research.
\end{abstract}

Keywords: citation analysis, co-authorship, research productivity, forestry

\section{RÉSUMÉ}

Dans le cadre de sa longue histoire, le Service canadien des forêts (SCF) a comme mandat de collaborer aux travaux de recherche et de partager les résultats de ces derniers. La publication dans des ouvrages scientifiques révisés par des pairs constitue un important élément de ce processus. Au moyen d'une base de données sur les publications du SCF réparties sur les cinquante dernières années, nous avons mis en évidence la persistance des publications de ce secteur du gouvernement du Canada. Le nombre moyen d'auteurs relevé dans la bibliothèque du SCF est passé de 1,4 auteurs par article au cours des années ' 60 et de 1,5 auteurs au cours des années '70, pour atteindre presque 5 auteurs par article entre 2010 et 2018. Notre étude a également noté les défis associés à l'analyse longitudinale des bases de données de citations. Dans les faits, l'utilisation d'une base courante de citations a relevé un nombre significativement plus faible d'articles produits par un seul auteur, et significativement plus d'articles produits par plus de vingt auteurs lors d'une comparaison avec la liste publique des « titres » offerts par le SCF. En fonctions des résultats obtenus, nous présentons plusieurs recommandations reliées à l'utilisation des bases de citations portant sur la diffusion des recherches effectuées en partenariat.

Mots clés : analyse de citations, corédaction, productivité en recherche, foresterie

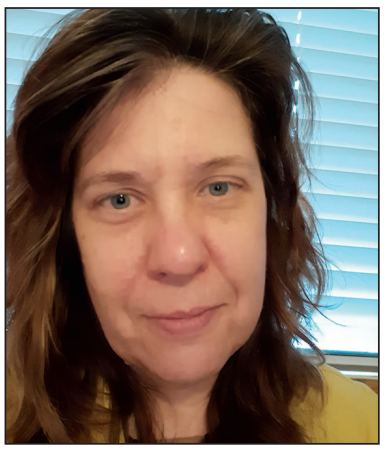

Heather MacDonald

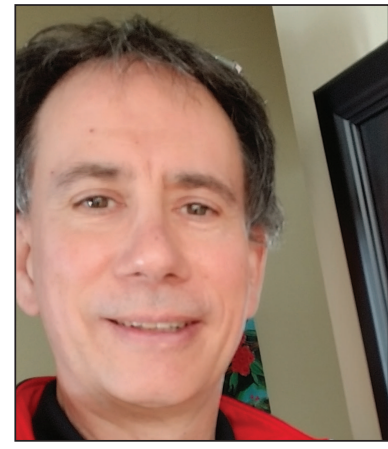

Daniel W. McKenney

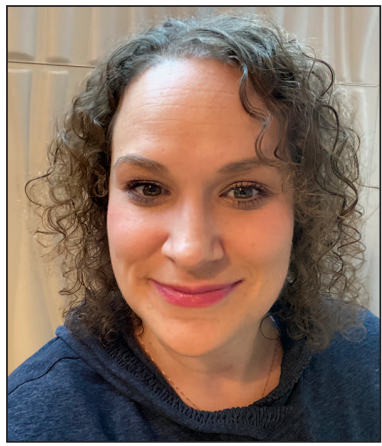

Kaitlin DeBoer

${ }^{1}$ Great Lakes Forestry Centre, Canadian Forest Service, Natural Resources Canada, Sault Ste. Marie, Ontario, Canada, P6A 2E5

${ }^{*}$ Heather.MacDonald4@Canada.ca 


\section{Introduction}

Research collaborations have become a management imperative. The National Academies of Sciences, Engineering and Medicine state that the greatest challenges facing humanity require insights from multiple disciplines (Institute of Medicine, 2005). The United Nations Educational, Scientific and Cultural Organization (UNESCO 2015) described "co-operation and collaboration between scientists" as a hallmark of world class science, and concluded that "scientists now live in a hyper-connected world" (2015, p. 3). As measured by coauthorship, collaboration has been on the rise: for instance, Nature reported that its Letters now have four times as many authors as they did 60 years ago (Adams 2012).

In Canada, a number of studies have examined the research contribution of industry, university, and government sectors. A 2015 report from the United Nations Educations, Scientific and Cultural Organization (UNESCO) noted decreasing Canadian government participation in research (UNESCO 2015; see as well Kinder and Welsh 2012). A recent PLOS ONE article by Larivière et al. (2018) concluded that there has been a rise in partnerships between university and other sectors in Canada, but a reduction in basic (as opposed to applied) research publications from government and the private sector.

In part, the recorded decline in government share of research can be linked to a number of debates that have shaped the Canadian research environment related to the role of government science. In 1988, the Canadian National Advisory Board on Science and Technology (NABST 1988) recommended shifting resources to industry-based research from government science. By the mid-1990s, the NABST stated that the "federal government should promote partnerships and collaboration among S \& T stakeholders" (NABST 1995). "Innovation systems" were encouraged to reflect interactions between the sectors, as exemplified by the Networks of Centres of Excellence (Atkinson-Grosjean 2006). The focus on applied research increased between 2009 and 2014 with policy shifts at the National Research Council (Council of Canadian Academies 2018) and earlier at NSERC (as illustrated in Cozzarin 2006).

However, arguably not all federal government departments experienced the same type of decline noted by Kinder and Walsh (2012) regarding the NRC. For instance, the Government of Canada has a long-standing role in forest science with the Canadian Forest Service (CFS) being the main player. CFS is a sector within Natural Resources Canada (NRCan), a federal government department that deals with a broad suite of natural resource issues. Current elements in the CFS research program include the study of native and non-native forest insects and diseases, aspects of forest fire behaviour and management, science in support of sustainable forest management, climate change mitigation and adaptation in the forest context, and cumulative effects of anthropogenic and non-anthropogenic disturbances on forests (NRCan 2019).

\section{Measuring collaboration}

The measurement of collaboration, according to Abramo et al. (2009), is typically done using either a qualitative approach (through case studies), or a quantitative approach via "analysis of co-authorship of scientific papers published in international journals and indexed in specialist databases" (p. 156). However, some authors have argued against the use of citation databases to track trends across research fields, institutions, countries, or time periods (Harzing and Alakangas 2016; Calver et al. 2017). Calver et al. (2017) urged attention to "errors and idiosyncrasies in individual databases that affect data retrieval and conclusions" (p. 19).

\section{Purpose of the current paper}

In this paper, we present an empirical analysis of the historical contribution of the CFS to assess the extent to which the federal government contribution towards forestry science has remained consistent over time, or whether this field has declined as other agencies as documented at the NRC. Consistent with other research, we have focused on co-authorship trends as a metric for collaboration.

For our analysis, we use the Canadian Forest Service Publications Database which is a repository of publications authored or co-authored by CFS employees (the CFS "bookstore"). This paper includes: a) a description of trends over time in collaboration at the CFS from 1966 to 2018; and, b) an assessment of whether Scopus data (Elsevier 2019) provides a complete picture of co-authorship at the CFS by comparing CFS records (i.e., the CFS "bookstore") to Scopus data for CFS-affiliated authors. In so doing, we illustrate challenges associated with longitudinal analysis of citation databases, and provide several conclusions for use of Scopus, particularly when pulling records by affiliation.

\section{Methods}

The available CFS bookstore of publications from 1966 to 2018 (https://cfs.nrcan.gc.ca/publications) was used if the publication was a journal article. CFS series items, contributions to proceedings, monographs, book chapters, and "miscellaneous" items from the CFS bookstore were not included. A review of the CFS bookstore indicates that a relatively small number of publications classified in CFS as journal articles were more similar to magazines or newsletters rather than peer-reviewed journals (listed in Table 1). Because we were primarily interested in journal articles, we removed the publications listed in Table 1 from subsequent analyses.

The CFS bookstore data was linked by journal title to journal category, as published by SCImago (2019). The SCImago portal categorizes journals into 313 subject categories and ranks 31971 journals. In cases where the CFS-recorded journal name differed from the SCImago data, the CFS-recorded journal name was edited to match SCImago. We also extracted data from Elsevier (2019) Scopus scientific literature citation database if at least one of the authors listed was affiliated with CFS. Scopus data were retained for the analysis if the publication was identified as an article, article in press, editorial, letter, note, review, or a short survey. Books, book chapters, conference papers and erratum were excluded from the Scopus analysis.

R Core Team (2017) was used for developing the boxand-whisker plots. SAS software, Version 9.4 of the SAS System for Windows was used to merge Scopus, SCImago, and CFS data. A one-way (ANOVA) was conducted on: a) number of authors by publication decade; and, b) number of authors in CFS versus Scopus data. Chi-square tests of significance were requested in SAS (PROC FREQ) for analyses of 
categorical data including journal concentration by time period. A t-test was implemented on the average number of authors per article by data source, and Pearson's correlation coefficient was calculated between journal rank and number of authors.

Two linear regressions were carried out to test the explanatory contribution of year of publication as a predictor for number of authors. The form of the first regression model is:

$$
\hat{y}_{i}=\beta_{0}+\beta_{1} x_{1}+\varepsilon_{i}
$$

Where $\hat{y}_{i}=$ the number of authors for the ith journal article; $\beta_{0}=$ the intercept; $\beta_{1}=$ year of publication; and $\varepsilon_{\mathrm{i}}$ is the error term reflecting all other factors affecting the dependent variable.

Because authors such as Harzing and Alakangas (2016)

Table 1. Non-peer reviewed publications in the CFS database

\begin{tabular}{lc}
\hline Journal & $\begin{array}{c}\text { Number of } \\
\text { CFS-affiliated } \\
\text { articles, 1966-2018 }\end{array}$ \\
\hline Bimonthly Research Note(s)/ Progrès forestie, & 186 \\
Canadian Forestry Service Research Note, & \\
Bi-Monthly Research Bulletin, Bi-monthly & \\
Progress Report, Rev. Bimest. Rech. & 11 \\
Canadian Silviculture & 3 \\
Reforestation Notes & 32 \\
Milieu & 7 \\
Mosquito News & 7 \\
Le Soleil & 2 \\
Evergreen & 9 \\
Atlantic Forestry Review & 4 \\
BC Forest Professional & 10 \\
l'Aubelle & $\mathbf{2 6 2}$ \\
\hline Total & \\
\hline
\end{tabular}

conclude that publication patterns often differ by discipline, a second regression incorporated binary predictor variables indicating publication in SCImago journal subject categories with more than 500 CFS articles. The SCImago journal rank as a predictor was included for the number of authors in the second regression model.

\section{Results}

CFS publications by journal

There are 10857 records in the CFS bookstore classified as journal articles from 1966 to 2018. The CFS publication record used for this analysis extends for five decades. Table 2 presents journals with more than 20 articles affiliated with CFS between 1966 and 2018, or more than 10 articles in the past twenty years. There are twenty-two journals with one or more CFS-affiliated articles in each decade between the 1960s and the 2010s (bolded rows in Table 2). For example, The Canadian Entomologist, The Forestry Chronicle, The Journal of Invertebrate Pathology, Phytoprotection and Forest Science have articles in each decade between 1966 and 2018. However, the share of journals with CFS representation every decade is declining as a proportion of all CFS articles, representing $52.5 \%$ from 1970 to 1979 , compared to $25.6 \%$ in 2000 to 2009 .

\section{Number of authors per article}

The average number of authors reported in the CFS bookstore increased from 1.4 per article in the 1960s and 1.5 in the 1970 s to just under five authors per publication from 2010 to 2018 , a significant difference by decade $(\mathrm{F}=437.28, \mathrm{p}<0.0001$, Fig. 1). Only $11 \%$ of articles from 2010 to 2019 were written by one person while $30 \%$ of articles published during this period were authored by six or more people. Of the 35 articles recorded in the CFS bookstore with 20 or more authors, 29 of them were published after 2010 .

Fig. 2 shows a relatively constant (linear) increase over time in the number of authors. As well, Fig. 3 illustrates the average number of authors per article for the most common journal categories. As can be seen from Fig. 3, a trend towards increasing number of authors is evident across all six journal

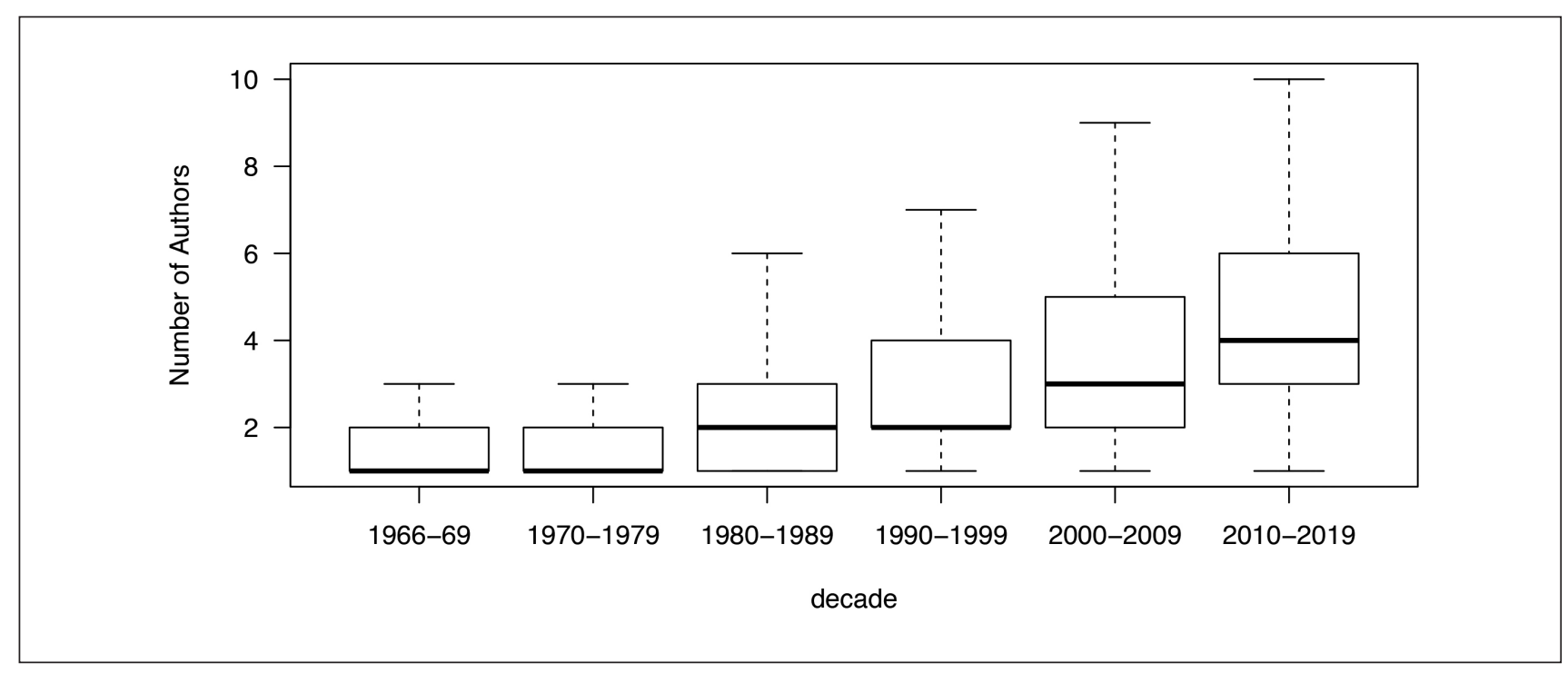

Fig. 1 Number of authors by publication decade 
Table 2. Journals with more than 20-CFS authored/co-authored articles from 1966 to 2018 , or more than 10 CFS articles published after 2000. The columns represent the number of CFS-authored (co-authored) articles by decade from 1966 to 2018.

Rows that contain bolded text represent journals with articles in each time period

\begin{tabular}{|c|c|c|c|c|c|c|c|}
\hline Journal & $1966-69$ & $1970-79$ & 1980-89 & 1990-99 & 2000-09 & 2010-18 & Total \\
\hline Canadian Journal of Forest Research & - & 199 & 231 & 268 & 228 & 148 & 1074 \\
\hline Canadian Entomologist & 127 & 246 & 170 & 146 & 104 & 67 & 860 \\
\hline Forestry Chronicle & 54 & 124 & 143 & 204 & 214 & 93 & 832 \\
\hline Canadian Journal of Botany & 105 & 136 & 82 & 52 & 42 & - & 417 \\
\hline Forest Ecology and Management & - & 2 & 9 & 64 & 113 & 121 & 309 \\
\hline Journal of Invertebrate Pathology & 42 & 67 & 16 & 19 & 15 & 11 & 170 \\
\hline Canadian Journal of Plant Pathology & - & 2 & 32 & 48 & 34 & 8 & 124 \\
\hline Phytoprotection & 11 & 25 & 28 & 16 & 26 & 4 & 110 \\
\hline Forest Science & 15 & 19 & 14 & 24 & 16 & 19 & 107 \\
\hline Environmental Entomology & - & 5 & 18 & 30 & 19 & 32 & 104 \\
\hline Journal of the Entomological Society of British Columbia & 21 & 13 & 34 & 19 & 9 & 5 & 101 \\
\hline Journal of Environmental Science and Health & - & 4 & 37 & 58 & 1 & - & 100 \\
\hline Plant Disease Reporter/Plant Disease/Plant Disease Report & 42 & 22 & 15 & 9 & 7 & 3 & 98 \\
\hline Phytopathology & 8 & 20 & 14 & 25 & 20 & 7 & 94 \\
\hline Tree Physiology & - & - & 3 & 41 & 39 & 8 & 91 \\
\hline Canadian Journal of Zoology & 7 & 42 & 25 & 10 & 3 & 3 & 90 \\
\hline Ecological Modelling & - & - & 6 & 11 & 39 & 33 & 89 \\
\hline Remote Sensing of the Environment & - & - & 1 & 4 & 38 & 46 & 89 \\
\hline Canadian Journal of Remote Sensing & - & 1 & 4 & 19 & 33 & 31 & 88 \\
\hline Canadian Journal of Soil Science & 4 & 16 & 13 & 17 & 29 & 9 & 88 \\
\hline Journal of Economic Entomology & 5 & 12 & 15 & 12 & 13 & 23 & 80 \\
\hline Canadian Journal of Microbiology & 15 & 30 & 13 & 8 & 6 & 1 & 73 \\
\hline Journal of Chemical Ecology & - & 3 & 16 & 23 & 11 & 11 & 64 \\
\hline Mycologia & 14 & 14 & 5 & 10 & 7 & 4 & 54 \\
\hline Journal of Insect Physiology & 1 & 6 & 5 & 14 & 13 & 12 & 51 \\
\hline Journal of Geophysical Research & - & - & 1 & 14 & 14 & 17 & 46 \\
\hline New Forests & - & - & 4 & 25 & 8 & 8 & 45 \\
\hline European Journal of Forest Pathology & - & 9 & 10 & 21 & 2 & 1 & 43 \\
\hline Silvae Genetica & 2 & 5 & 14 & 16 & 5 & 1 & 43 \\
\hline Water, Air and Soil Pollution & - & 2 & 13 & 21 & 6 & - & 42 \\
\hline Agricultural and Forest Meteorology & - & - & 2 & 8 & 14 & 16 & 40 \\
\hline Entomologia Experimentalis et Applicata & 1 & 1 & 6 & 11 & 7 & 14 & 40 \\
\hline Soil Science Society of America Journal & 3 & 6 & 9 & 4 & 7 & 10 & 39 \\
\hline Forestry & - & 1 & 2 & 5 & 10 & 19 & 37 \\
\hline International Journal of Remote Sensing & - & - & 1 & 6 & 18 & 12 & 37 \\
\hline Northern Journal of Applied Forestry & - & - & 4 & 22 & 10 & 1 & 37 \\
\hline Plant and Soil/Plant Soil & 3 & 6 & 7 & 8 & 7 & 5 & 36 \\
\hline Canadian Journal of Chemistry & 2 & 9 & 9 & 12 & 1 & - & 33 \\
\hline Pesticide Science & - & - & 15 & 18 & - & - & 33 \\
\hline Soil Biology and Biochemistry & - & 2 & 7 & 8 & 8 & 8 & 33 \\
\hline Annals of the Entomological Society of America & 3 & 18 & 2 & 4 & 3 & 2 & 32 \\
\hline New Phytologist & 1 & 4 & 7 & 5 & 7 & 8 & 32 \\
\hline Scandinavian Journal of Forest Research & - & - & 3 & 10 & 11 & 8 & 32 \\
\hline Canadian Field-Naturalist & 3 & 5 & 13 & 6 & 4 & - & 31 \\
\hline Insect Biochemistry and Molecular Biology & - & 1 & - & 13 & 11 & 5 & 30 \\
\hline Journal of General Virology & - & 1 & - & 9 & 15 & 5 & 30 \\
\hline Ecology & 4 & 10 & - & 2 & 9 & 4 & 29 \\
\hline Journal of Applied Entomology & - & - & 1 & 11 & 11 & 3 & 26 \\
\hline Theoretical and Applied Genetics & - & - & 4 & 16 & 6 & - & 26 \\
\hline Canadian Journal of Plant Science & 4 & 7 & 2 & 2 & 5 & 4 & 24 \\
\hline Phytochemistry & 1 & 8 & 8 & 5 & 2 & - & 24 \\
\hline Canadian Plant Disease Survey & 1 & 10 & 6 & 1 & 4 & 1 & 23 \\
\hline Journal of Experimental Botany & - & 9 & 1 & 7 & 1 & 4 & 22 \\
\hline Physiologia plantarum & - & 1 & 6 & 12 & 3 & - & 22 \\
\hline \multicolumn{8}{|l|}{ Emerging Journals (no articles before 1990) } \\
\hline International Journal of Wildland Fire & - & - & - & 15 & 37 & 51 & 103 \\
\hline Zookeys & - & - & - & - & 17 & 67 & 84 \\
\hline Forests & - & - & - & - & - & 53 & 53 \\
\hline Global Change Biology & - & - & - & 1 & 16 & 34 & 51 \\
\hline PLoS ONE & - & - & - & - & 1 & 49 & 50 \\
\hline
\end{tabular}


Table 2. (continued)

\begin{tabular}{|c|c|c|c|c|c|c|c|}
\hline Journal & $1966-69$ & 1970-79 & 1980-89 & 1990-99 & 2000-09 & 2010-18 & Total \\
\hline Forest Pathology & - & - & - & - & 20 & 16 & 36 \\
\hline Ecological Applications & - & - & - & 6 & 8 & 21 & 35 \\
\hline Environmental Reviews & - & - & - & 4 & 10 & 18 & 32 \\
\hline Environmental Monitoring and Assessment & - & - & - & 9 & 16 & 6 & 31 \\
\hline Molecular Ecology & - & - & - & 2 & 8 & 12 & 22 \\
\hline BC Journal of Ecosystems and Management & - & - & - & - & 16 & 5 & 21 \\
\hline Ecosystems & - & - & - & - & 5 & 15 & 20 \\
\hline Tree Genetics \& Genomes & - & - & - & - & 6 & 13 & 19 \\
\hline Ecosphere & - & - & - & - & - & 18 & 18 \\
\hline Écoscience & - & - & - & 1 & 6 & 10 & 17 \\
\hline Remote Sensing & - & - & - & - & - & 16 & 17 \\
\hline Zootaxa & - & - & - & - & 5 & 11 & 16 \\
\hline Landscape Ecology & - & - & - & 1 & 3 & 12 & 16 \\
\hline Biological Invasions & - & - & - & - & 3 & 10 & 13 \\
\hline Global Ecology and Biogeography & - & - & - & - & 2 & 11 & 13 \\
\hline Environmental Research Letters & - & - & - & - & - & 12 & 12 \\
\hline Biogeosciences & - & - & - & - & 1 & 11 & 12 \\
\hline Total of Journals Listed & 499 & 1123 & 1106 & 1492 & 1468 & 1326 & 7015 \\
\hline All CFS Publications & 727 & 1711 & 1554 & 2259 & 2416 & 2229 & 10896 \\
\hline$\%$ of Total CFS-Affiliated Articles & $68.6 \%$ & $65.6 \%$ & $71.2 \%$ & $66.0 \%$ & $60.8 \%$ & $59.5 \%$ & $64.4 \%$ \\
\hline
\end{tabular}

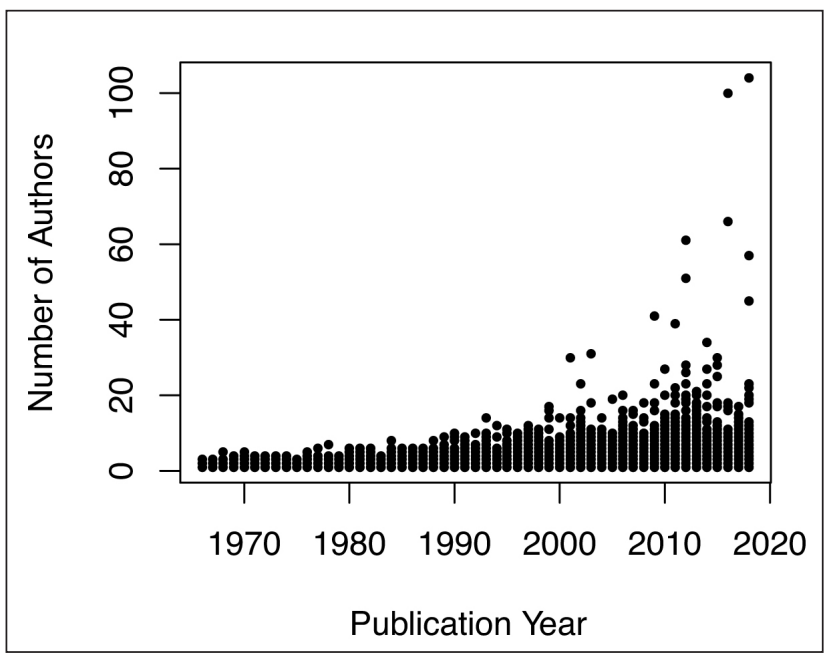

Fig. 2 Number of authors by publication year using the CFS Bookstore

subject categories considered. Journals categorized into Global and Planetary Change had the highest average number of authors for CFS-affiliated articles (5.3 authors per publication) from 2010 to 2018.

Journal rank was correlated to the number of authors, with better quality journals having a greater average number of authors $(\mathrm{r}=-0.196, \mathrm{p}<.0001)$. Restricting the analysis to 2010 to 2018 , the correlation between journal rank and number of authors is similar $(\mathrm{r}=-0.1508, \mathrm{p}<.0001)$.

The results of the regression model are presented in Table 3. For the simpler model which included only year of publication for the article registered in the CFS bookstore, the regression model accounted for $16.1 \%$ of the variability in the data.
The regression model was statistically significant $(\mathrm{F}=2039.0$, $\mathrm{p}<0.0001$ ). In comparison, introducing journal rank and common CFS journal subject categories (as defined by SCImago), did not produce a substantial improvement in the predictive ability of the regression model. The expanded regression model produced an $\mathrm{r}^{2}$ of $0.166(\mathrm{~F}=209.11$, $\mathrm{p}<0.001$ ), essentially equivalent to the more parsimonious model. This analysis, as well as Fig. 3, suggests that the relationship between year of publication and number of authors does not differ markedly across the subject areas included in the regression model.

\section{Comparison of CFS to Scopus data}

A comparison of Scopus and SCImago journals to those in the CFS bookstore identified that several publications with substantial contributions from the CFS were not in either SCImago or Scopus. As summarized in Table 4, neither SCImago nor Scopus included specialized publications such as The Entomological Society of British Columbia, Proceedings of the Entomological Society of Ontario, the Annales de la Société Entomologique du Québec, Manitoba Entomologist, and the Journal of the Acadian Entomological Society. Peer reviewed publications such as Insecta Mundi, Molecular Ecology Notes, Belgian Journal of Entomology, and Biotechnologie, Agronomie, Société et Environnement also did not link to Scopus or SCImago journals. Other publications such as the Canadian Plant Disease Survey did not return publications from Scopus, but do provide some significant historical contributions concerning the occurrence and severity of plant and tree diseases in Canada (Canadian Phytopathological Society 2019).

In total, 1706 articles in the CFS bookstore published from 1966 to 2018 did not match a SCImago or Scopus journal title (15.7\%). From 2002 to 2017, 324 publications did not match either a SCImago or Scopus journal $(8.1 \%$ of 3993 journal 
articles listed in the CFS bookstore), of which 75 are contained in Table 1. These articles represent an important, legitimate part of the publication record, particularly for analysis of co-authorship.

Data on affiliation were not available for many CFS articles until after 2000 (Fig. 4). As a result, we limited our anal-

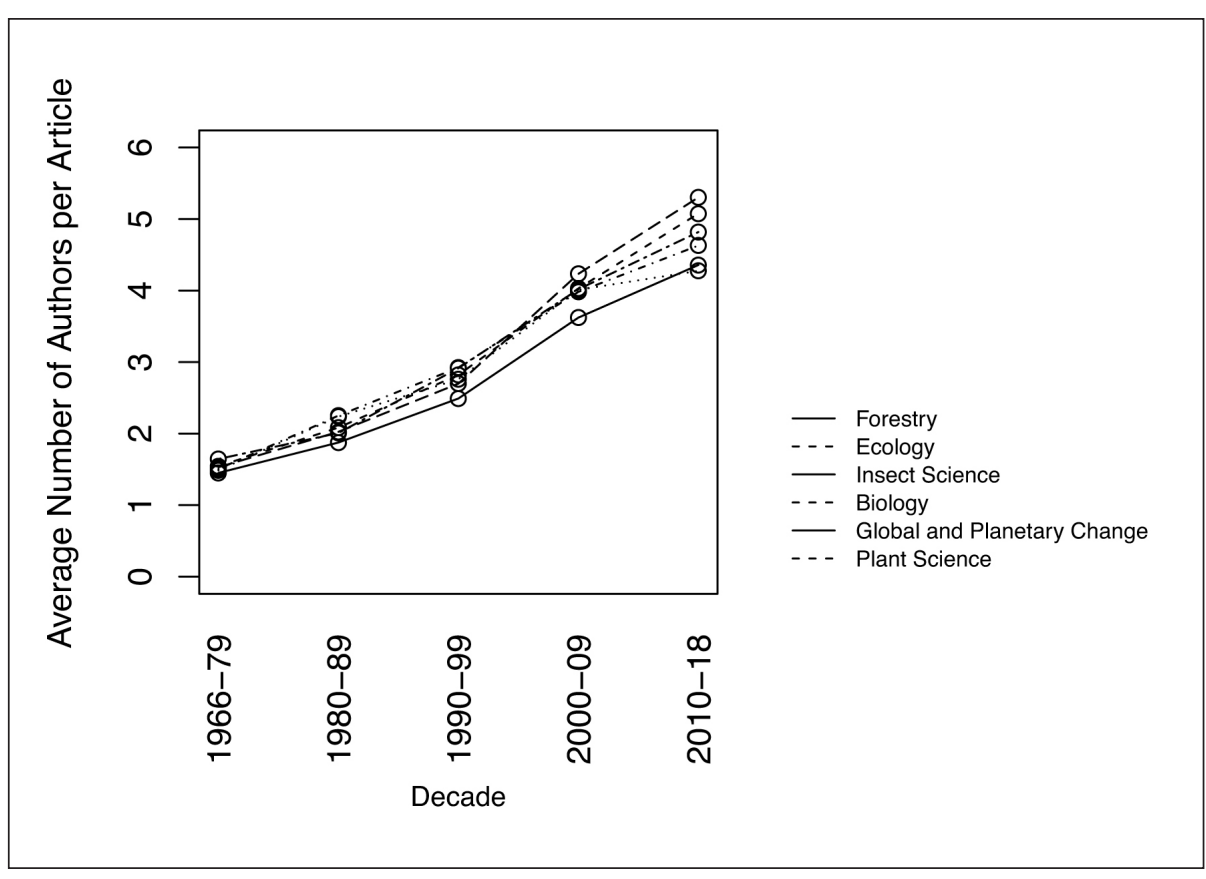

Fig. 3 Average number of authors on CFS-affiliated publications by decade by top journal subject categories

Table 3. Regression results for two models. The independent variable for Model 1 was the number of authors per article and the year of publication only. Model 2 independent variables included year of publication, journal rank, and a flag for the most common SCImago journal categories ysis using Scopus data to fifteen years from 2002 to 2017, as the coverage is relatively high over this time period. From 2002 to 2017, there are 4058 CFS-affiliated records in Scopus, or 65 more than recorded by CFS. This might be due in part to differences in the recorded year of publication, or with respect to which articles are considered primarily affiliated with the CFS (as opposed to a CFS author contributing to a Food and Agriculture Organization report, for instance). The coverage of CFS articles in Scopus varied from year to year.

Comparing CFS to Scopus data from 2002 to 2017, the Scopus record was more likely to contain articles authored by 20 or more people (50 articles) compared to the CFS record (29 articles). Of the fifty articles in Scopus with 20 or more authors, only 28 were in the CFS record $\left(\chi^{2}=5.80, p=.016\right)$. Instead, the CFS contained a greater number of articles authored by one person (395) compared to Scopus (205), a statistically significant difference $\left(\chi^{2}=58.90, \mathrm{p}<.0001\right)$.

Considering journals listed in Table 4 from 2002 to 2017, the average number of authors was three, compared to 4.5 in journals listed in SCImago or Scopus, significantly fewer

\begin{tabular}{|c|c|c|c|c|c|c|}
\hline & \multicolumn{6}{|c|}{ y: Number of Authors } \\
\hline & \multicolumn{3}{|c|}{ Model 1} & \multicolumn{3}{|c|}{ Model 2} \\
\hline & $\begin{array}{c}\text { Coefficient } \\
\text { Estimate }\end{array}$ & t-value & $\mathbf{p}$ & $\begin{array}{l}\text { Coefficient } \\
\text { Estimate }\end{array}$ & t-value & $\mathbf{p}$ \\
\hline Intercept & -159.77 & -44.29 & $<.0001$ & -153.061 & -31.69 & $<.0001$ \\
\hline X1: Year of Publication & 0.0817 & 45.16 & $<.0001$ & 0.079 & 32.67 & $<.0001$ \\
\hline X2: Journal Rank & - & - & - & -0.000069 & -9.03 & $<.0001$ \\
\hline X3-Forestry category & - & - & - & -0.715 & -8.21 & $<.0001$ \\
\hline $\mathrm{X} 4$ - Insect Science category & - & - & - & -0.442 & -3.74 & 0.0002 \\
\hline X5-Plant Science category & - & - & - & -0.266 & -2.40 & 0.01 \\
\hline X6-Global and Planetary Change category & - & - & - & 0.144 & 1.12 & 0.26 \\
\hline X7-Biology category & - & - & - & 0.095 & 0.74 & 0.46 \\
\hline Model R-Square & - & 0.1610 & - & - & 0.1657 & - \\
\hline Adjusted R-Square & - & 0.1609 & - & - & 0.1649 & - \\
\hline Root Mean Squared Error (RMSE) & - & 2.828 & - & - & 3.02649 & - \\
\hline
\end{tabular}


Table 4. Number of CFS-authored (co-authored) articles in non-Scopus journals

Number of

CFS-affiliated articles

Journal

1966-2018

Entomological Society of British Columbia

Proceedings of the Entomological Society of Ontario

Annales de la Société Entomologique du Québec

Manitoba Entomologist

Forêt et conservation (from 1966-1979)

BC Journal of Ecosystems and Management

Journal of the Acadian Entomological Society

Insecta Mundi

Belgian Journal of Entomology

Biotechnologie, Agronomie, Société et Environnement

ALCES

Open Journal of Forestry

Canadian Plant Disease Survey/

Inventaire des maladies des plantes au Canada

\begin{tabular}{lll}
\hline Total & 335 & 75 \\
\hline
\end{tabular}

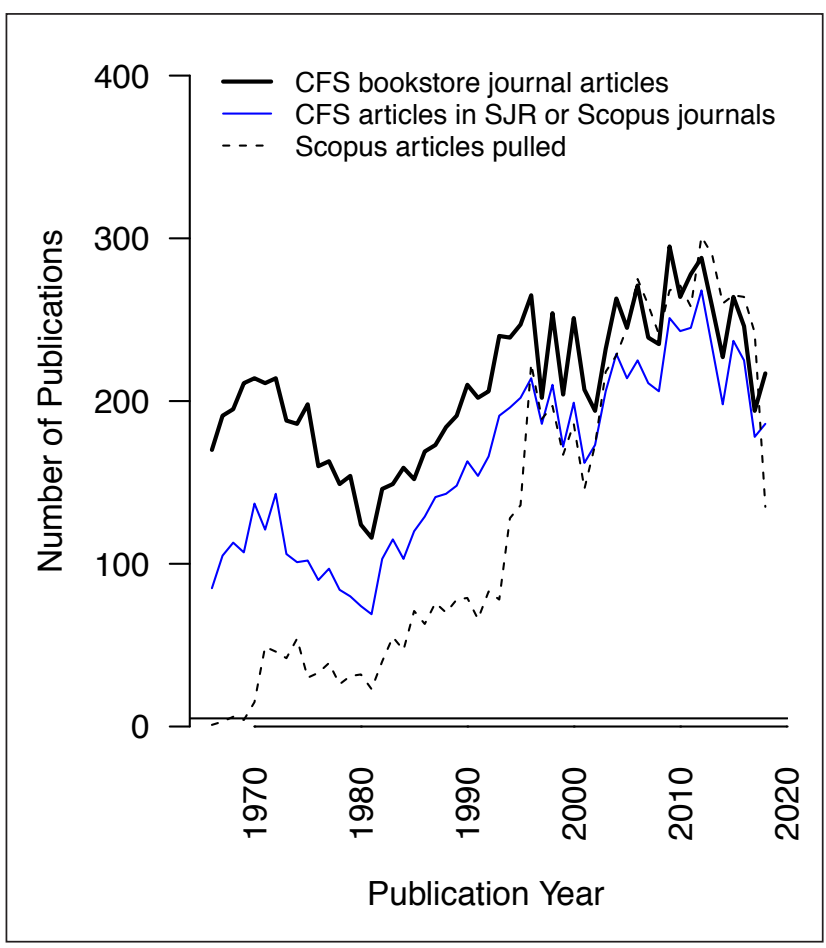

Fig. 4 Number of CFS-affiliated publications by year, as identified by SCOPUS and the CFS Bookstore

$(\mathrm{t}=102,66, \mathrm{p}<0.0001)$. As a result, the differences in coverage between Scopus and the CFS bookstore impact conclusions about the average number of authors per publication. Relying entirely on Scopus data would produce a bias towards a greater number of authors compared to the CFS record.

\section{Discussion}

Collaboration in science has become a management imperative to many organizations. Canada's federal science-based
2002-2017

departments and agencies are no exception. The CFS is but one modestly sized part of the federal government science family, but its reach is large given the complexity and geographic scope of environmental and forest management issues addressed by the sector. Here we have documented the CFS research enterprise using CFS data over a roughly fifty year span. As well, we have compared the CFS bookstore data to Scopus data.

Our analysis indicates that, given the sparsity of the Scopus record over much of the CFS publishing record, conclusions drawn about trends over time from this citation database should be interpreted with caution. Several publications such as proceedings from provincial associations are not listed by Scopus or by SCImago, yet reflect important periodicals related to forest science. Compared to the CFS record, Scopus contains significantly more papers authored by twenty or more people, and fewer papers authored by one person.

Our data are consistent with a relatively constant NRCan publication record noted by the Council of Canadian Academies (2018), and consistent with the traditional role played by the Canadian Federal Government in forestry noted by Larivière et al. (2018). Our data show that the CFS has produced over 1000 CFSauthored or co-authored papers from 1970 to 2018 published in the Canadian Journal of Forest Research, as well as over 800 articles in The Canadian Entomologist and The Forestry Chronicle. This represents a significant contribution to these Canadian journals.

Increasing authorship fractionalization is clearly evident in the CFS' own data. We showed a three-fold increase in the number of authors per publication over the past fifty years. Such increasing collaboration is consistent with trends such as the one noted by Nature (Adams 2012), and with imperatives issued by bodies such as UNESCO and the Institute of Science. Given the Federal Government's roles in science and policy nationally and internationally, this evolution is not surprising. However, use of citation databases should be used with some caution. Particularly for co-authorship analysis, it appears that attention should also be paid to lower ranking journals which may present preliminary investigations which in turn lead to more structured collaborative studies. For research on collaboration alone, there is an argument that the journals produced by the Societies of Entomology should be added to the Scopus record. Our future investigations will look at these and other publications in the "grey literature" to investigate the role of research outside citation databases to determine what impact some of these studies might have had on policy decisions.

Based on our findings, we recommend the following considerations when using Scopus data:

1) Data extractions from Scopus that rely on affiliation should be scrutinized for completeness of the record, particularly prior to 2000. As Fig. 4 shows, while journals are present in the Scopus data, extracting records based on affiliation fields may result in a limited data pull. As Sco- 
pus updates are introduced (e.g., Elsevier 2015), this time period may expand back in time; and,

2) Evidence of collaborations can be found in records of conferences, working papers, and in particular for entomology research, at the regional Societies of Entomology. Peer reviewed articles are one example of collaborations, but particularly for tracking emerging partnerships, it may be more useful to consider joint contributions in publications not tracked in Scopus. This will be the subject of our next exploration of collaboration at CFS.

Certainly, it is the sum total of the entire written historical legacy and interpersonal relations between agencies that influence the impact of science-based products. Impact of research activities on social, environmental and economic conditions is (arguably) the end goal of science investments. Better understanding the nuanced linkages between publications, collaborative science and impact in the non-science world will ultimately promote greater knowledge uptake. Codiscovery during collaboration produces knowledge that is owned and used by multiple partners. Our future efforts will investigate qualitative examples of research uptake in the CFS context.

\section{Acknowledgements}

We would like to thank Ed Banfield for extracting the Scopus data, as well as Maria Teresa Fernandez de Castro for discussions and interest in the subject. Thanks also go to Liam Miller for input on an earlier draft of the paper, and Meghan Sloane for her editorial assistance. Any remaining errors are the responsibility of the authors.

\section{References}

Abramo, G., C.A. D'Angelo and F. Di Costa. 2009. Research collaboration and productivity: Is there correlation? Higher Education 57(2): 155-171. doi:10.1007/s10734-008-9139-Z

Adams, J. 2012. Collaborations: The rise of research networks. Nature 490(7420): 335-336. doi:10.1038/490335a.

Atkinson-Grosjean, J. 2006. Public science, private interests: Culture and commerce in Canada's networks of centres of excellence. University of Toronto Press, Toronto.

Calver, M.C., B. Goldman, P.A. Hutchings and R.T. Kingsford. 2017. Why discrepancies in searching the conservation biology literature matter. Biological Conservation 213: 19-26. doi:10.1016/ j.biocon.2017.06.028

Canadian Phytopathological Society. 2019. Canadian Plant Disease Survey [online]. Available from https://phytopath.ca/publication/cpds/
Council of Canadian Academies. 2018. Competing in a Global Innovation Economy: The Current State of R\&D in Canada. Expert Panel on the State of Science and Technology and Industrial Research and Development in Canada, Council of Canadian Academies, Ottawa.

Cozzarin, B. P. 2006. Performance measures for the socio-economic impact of government spending on R\&D. Scientometrics 68(1): 41-71. doi:10.1007/s11192-006-0083-3

Elsevier. 2015. Breaking the 1996 barrier: Scopus adds nearly 4 million pre-1996 articles and more than 83 million references. Available from: https://blog.scopus.com/posts/breaking-the-1996-barrierscopus-adds-nearly-4-million-pre-1996-articles-and-more-than-83 [Accessed April 17th, 2017].

Elsevier. 2019. Scopus content at a glance [online]. Available from https://www.elsevier.com/solutions/scopus/how-scopusworks/content

Harzing, A. and S. Alakangas. 2016. Google scholar, Scopus and the Web of Science: A longitudinal and cross-disciplinary comparison. Scientometrics 106(2): 787-804. doi:10.1007/s11192-015-1798-9 Institute of Medicine. 2005. Facilitating Interdisciplinary Research. The National Academies Press, Washington, DC. https://doi.org/ $10.17226 / 11153$

Kinder, J. and F. Welsh. 2012. Performing strategic science in the public interest: Updating the policy debate regarding government science. Scientia Canadensis 35 (1-2): 135-149. https://doi.org/ 10.7202/1013984ar

Larivière, V., B. Macaluso, P. Mongeon, K. Siler and C.R. Sugimoto. 2018. Vanishing industries and the rising monopoly of universities in published research. Plos One 13(8): e0202120-e0202120. doi:10.1371/journal.pone.0202120

NABST. 1988. [National Advisory Board for Science and Technology]. Industry Committee Report, Ottawa.

NABST. 1995. [National Advisory Board for Science and Technology]. Healthy, wealthy and wise: A framework for an integrated federal science and policy strategy. Ottawa.

NRCan. 2019. About the Canadian Forest Service. Available from: https://www.nrcan.gc.ca/our-natural-resources/forests-forestry/ about-canadian-forest-service/17545. [Accessed September 5, 2019]. R Core Team. 2017. R: A language and environment for statistical computing [online]. R Foundation for Statistical Computing, Vienna, Austria. Available from https://www.R-project.org/

Scimago. 2019. Scimago Journal \& Country Rank [online]. Available from https://www.scimagojr.com/journalrank.php. [Accessed July 30, 2019].

UNESCO. 2015. UNESCO science report: towards 2030 [online]. Available from https://unesdoc.unesco.org/ark:/48223/pf0000235406/ PDF/235406eng.pdf.multi. [Accessed August 9, 2019]. 